\title{
IMPLEMENTATION OF THE REFERENCE CLASS FORECASTING METHOD FOR PROJECTS IMPLEMENTED IN A CHEMICAL INDUSTRY COMPANY
}

\author{
Renata Walczak, Tomasz Majchrzak*
}

\begin{abstract}
The purpose of this article is to present an industrial application of the Reference Class Forecasting Method (RCFM) developed by Kahneman and Tversky for planning and decisionmaking under uncertainty. Project plans are usually prepared on the basis of detailed calculations and arrangements according to selected project management methodology. Undertakings that are planned in this manner often fail and do not achieve their goals. However, the American Planning Association recommends using the RCFM as an additional method. The article presents four groups of projects implemented by a chemical industry company over four years. A few of the projects were accomplished according to the plan in terms of triple constraint i.e. time, cost, and scope. The cost aspect was taken into account in the paper. During the study, the planned and implemented costs of 222 projects were analysed. On the basis of the distribution of cost overruns, according to RCFM, new patterns of planned costs were prepared. The Reference Class Forecasting Method, which was effective for large homogeneous projects turned out to be completely useless for various projects implemented by the chemical company.
\end{abstract}

Keywords: risk management, quantitative methods \& models, technology management, Reference Class Forecasting

JEL Classification: G32, D81

\section{Introduction}

Concern about executing projects on time and within a planned framework has become the central issue of many project management methodologies: PRINCE2 introduces a management framework in order to make project success more probable where project success is defined as meeting the project objectives and customer requirements. This is measured in six fields: budget, schedule, quality, scope, risk, and benefits. Success cannot often be evaluated before a project's full implementation of the planned results since projects help organisations improve business as usual and deliver benefits to them (OGC, 2009; Hinde, 2012). The standard published by the Project Management Institute defines project success as meeting or exceeding customers' expectations by fine-tuning competing requirements such as costs, duration, scope, and quality (PMBOK, 2008; Dinsmore and Cabanis-Brewin, 2010). Different methodologies define various activities concerning achieving project success and address internal planning and project management. All methodologies present the fundamentals of project management in extensive detail, which should help to apply the standards in the real world. Project managers, especially new managers, have problems

* Warsaw University of Technology, College of Economics and Social Sciences (renata.walczak@pw.edu.pl); Basell Orlen Polyolefins Sp. z o.o. (Tomasz.Majchrzak@basellorlen.pl). 
with meeting all the requirements of methodologies. The remedy for the problems may be to increase the number of professional associations and introduce project management certifications. Stackpole claims that two weeks of preparation for the certification is insufficient and that only six months of study, reading the books on methodologies many times, working in the labs, and taking special courses should be completed in order to pass the exam (Stackpole, 2013). Despite becoming acquainted with the methodologies and the strict implementation of the plans, projects are not implemented in accordance with the assumptions and the project goals cannot be achieved (Flyvbjerg et al., 2002). After Goldratt introduced the theory of constraints, a new critical chain method of managing projects was accepted by professionals and now there is no obligation to prepare sophisticated and detailed plans. Project teams are free to choose appropriate methods to achieve project goals. The method attempts to take into account the impact of external factors on projects (Goldratt, 1997; Leach, 2014). In a quantitative manner, this impact is taken into account in the Reference Class Forecasting Method (RCFM) (Kahneman, 2011).

This paper presents an attempt to apply the RCFM to new project planning in a chemical company. Several projects executed in the company over four years were taken into consideration in order to create reference classes and check the results. Although in many cases, the method has been successfully used; in the case of the chemical company, the desired result was not achieved.

\section{Literature Review}

In many cases, large companies use simple deterministic planning methods based on a onetime assumption. Unfortunately, real projects are not generally implemented as planned. Flyvbjerg (2003) has rated many large projects in terms of delays and excessive costs incurred. Approximately 250 large projects from the last 70 years were examined and $90 \%$ of these cost more and lasted longer than was planned. Costs, compared to the plan, went up by $20 \%$ to $50 \%$ depending on the project. If the poor performance of the projects was the reason for such a condition, then this could be easily corrected by better management and implementing project management methodology. Unfortunately, the management did not learn from the mistakes made in earlier projects although it was possible to have a sense of the impending overruns (Flyvbjerg, 2003). Numerous studies have been conducted aimed at discovering the reasons for this situation. The Standish Group Report (Hastie and Wojewoda, 2015) showed that failures are frequently covered up and ignored. The report indicated many reasons for project failures: uncertainty associated with planning, unreliable data, inadequate planning models, lack of management and project contractor involvement, lack of vision, clear targets and realistic requirements for workers, lack of proper planning skills, difficulties with milestones and checkpoint definitions, lack of competent personnel, unwillingness to work, and the random variability of project requirements.

All those problems could have been corrected with the proper use of project management methodology; however, this did not work. Other studies showed that the method of scheduling based on deterministic data was insufficient. In order to better evaluate the project, stochastic analysis methods, e.g. stochastic models or the Monte Carlo method, should be used. In this case, task duration, costs, and other independent variables should be described by probability distributions. The calculations of the model were made several times and based on the results, the probability distributions of project 
costs and duration were determined. Such planning might have resulted in values closer to reality. In this case, the condition for success was to obtain reliable historical data (Dimov and McKee, 2007; Abrams, 2010).

Kahneman (2011) identified psychological and political reasons for not completing projects on time and within budget. He noted that a person tends to have a too optimistic view of the world. This atavistic attribute allowed survival. If people remember all the failures, and considered all negative consequences that may result from actions taken, they would have never discovered new lands and never engaged in new projects. For political reasons, Kahneman indicated a desire to obtain financing for the projects. Presenting optimistic plans could persuade policymakers to grant the funds. Later, after starting the project, especially in case of large projects, closing them is impossible and additional unplanned costs must be incurred. Besides the reasons presented above, external factors influencing project costs and duration are presented: rising prices for materials, significant new expenses, new services, unplanned tasks, changing economic conditions etc. In the case of large projects, incorrect planning can cause economic, social, environmental, and security consequences. In order to estimate the real costs and schedules, Kahneman and Tversky (2000) developed the Reference Class Forecasting Method for planning and decision-making under uncertainty. RCFM takes into account project plans and also considers similar projects executed earlier. Cost overruns and time limits resulting from the implementation of historic projects should be proportionally added to the current estimates. This would work only when policymakers would have a real picture of the future. This method was applied for the first time by Flyvbjerg et al. (2004) for large infrastructure projects.

The forecasting method using reference classes includes: collection of historical data; grouping similar data in the reference classes; it must be proven, using appropriate statistical tests or other methods, that values belonging to individual classes fully reflect comparable groups of projects; classes cannot be too broad because the inference on the basis of these types of classes may not be accurate enough; the classes must also not be too narrow because there could be problems with available data and the ability to assign new projects to a particular class; finding probability distributions of cost and schedule overruns for each reference class; finding a suitable scaling factor, which can be used to assess future plans (Flyvbjerg, 2011).

A new project plan should be created using standard methods and afterwards, it should be corrected using the values based on the reference class. The forecasting method using reference classes is recommended by the American Planning Association as an additional method used for planning. Project managers are encouraged to collect and archive data regarding all projects and use it for future planning (Flyvbjerg, 2003).

\section{Research Objectives}

The objective of this paper is to present the use of the Reference Class Forecasting Method in a chemical company. Previous work regarding RCFM has focused only on large projects (Flyvbjerg et al., 2004, 2005; Fridgeirsson, 2009). This seems reasonable because it is easier to compare projects of the same size and type. It is also easier to group projects in classes of a similar category. In addition, the RCFM involves a large amount of work, is time-consuming, and often technically difficult. Its use is unprofitable because the savings are too small in relation to expenditure although the method has not been 
used to assess small projects for the reasons mentioned above. In this paper, an attempt was made to check the relevance of its application. According to Flyvbjerg's analysis (Flyvbjerg, 2004) nearly all projects do not meet their goals, so why not use RCFM for smaller ones? The objective for this research was to use the method for small projects executed in the chemical company, build a model that could be used for forecasting, analyse the exactness of the cost plans of chemical company projects, and recommend the future implementation of the method for smaller projects.

There remains a need for effective project planning and since the RCFM is recommended by the American Planning Society, the method was examined for the chemical company's projects.

\section{Methodology}

The analysis presented in this paper was prepared for one specifically selected chemical company that conducts all activities as projects. Due to confidentiality reasons, the company only provided general data regarding its undertakings. The projects were divided arbitrarily by the company into five groups (denoted as $\mathrm{A}, \mathrm{B}, \mathrm{C}, \mathrm{D}$, and $\mathrm{E}$ ) depending on the purpose and scope of the work. A unique feature of this research is that all projects were executed by one company using a limited number of subcontractors. The projects selected for the analysis are typical for any chemical company. Group A was in regard to improving logistics operations in the company. The projects focused on optimising loading and unloading operations, increasing efficiency, and improving the safety of workers and drivers. The company reported that construction projects, building renovations, roads repairs, installing additional facilities on site were included in this group. The projects for group A were executed on a regular basis every year. It was easy to develop project schedules, which were frequently repetitive, and the requirements for contractors' special skills were reduced in comparison to the chemical industry standards as they mostly involved assembly, construction, and groundwork.

Groups B, C, and D could be considered together. They strictly referred to the manufacturing areas. Key types of projects were the modernisation of tanks, vessels, apparatus and equipment, reconstruction of pipelines, and installing the fittings in piping systems. Projects for these groups were comprehensive and required inter-branch coordination at the design and implementation phase. These types of projects were usually implemented when the plant was out of operation - during scheduled and preventive maintenance shutdowns when the installations were accessible. Unpredicted overhauls, not previously planned in the company, might have resulted in additional scope and costs; hence there was an intensification of work in certain periods and stagnation in others. These types of projects had to be carefully planned and scheduled and there were high requirements placed on the subcontractors. As a consequence, the number of companies utilised was limited. The split between B, C, and D applied to a different section of the manufacturing division although the types of projects in each group were the same. In addition, the same subcontractors were employed for each group.

Group E aggregated relatively simple projects such as purchasing turnkey systems, the assembly of readymade installations (plug and play), cross-sectional projects regarding production, and primarily IT operations. These projects rarely required complex plans and permits. Implementation of these projects is dependent on the subcontractors or the providers' availability rather than on internal restrictions as in groups $\mathrm{B}, \mathrm{C}$, and D. 
For the purposes of this analysis, it was assumed that all actions relating to the projects started from the beginning of the financial year, i.e. from January and that all projects lasted one year. It was forbidden to spend money before the official start of the project; thus, the only possible action was to identify potential subcontractors and collect their quotations.

The project budgets contained all costs associated with documentation, project plans, and implementation (usually by the supplier, subcontractor or service). The budgets did not formally assume any official reserves. The differences $+/ 30 \%$ were acceptable on the project charter stage, which is acceptable accuracy at that stage of planning in this industry. It was expected in the chemical company that final plans were accurate and had exact budgets. There were no hidden "buffers" at the final stage.

Taking the information provided by the company at face value, the RCFM was applied to forecast future cost overruns in the presented groups. The costs overruns C_o were calculated according to the following formula:

$$
C_{o}=\frac{\left(C_{R}-C_{P}\right)}{C_{P}}
$$

where

$\mathrm{C} \_\mathrm{o}-$ relative costs overruns,

$\mathrm{C}_{-} \mathrm{R}$ - costs of project realisation, EUR,

C_P - planned costs, EUR.

The best method was to fit a probability distribution to empirical data regarding the years 2012 to 2014; however, this was not always possible due to insufficient data regarding distinguished groups. In this case, it was necessary to rely on empirical distributions. The aim was to find a required optimism bias uplift for classes of projects considered in 2015. The company has executed many projects since it was possible to assume that there was $50 \%$ chance of exceeding forecasted costs. In this case, the average uplift of the reference class would be used for predicting the uplift of new projects implemented in 2015.

\section{Results}

In 2012, the selected chemical company implemented 65 projects. Over the years, the number of projects has decreased by $30 \%$ and was equal to 62 in 2013, 49 in 2014, and 46 projects in 2015; additionally, the budgets were smaller each year. In 2012, more money was spent than planned (Chart 1). During subsequent years, the situation was different, partly due to improved planning and market conditions. The total value of planned projects decreased by 35\% between 2012 and 2015 although the total value of implemented projects decreased by 52\% (Chart 1) in the same period. In Chart 2, it can be observed how the average value of a project decreased over the years. Again, 2012 was the only year when the average value of a project exceeded the budget. Data presented in Charts 1 and 2 refers to all 222 projects implemented in 4 years.

Expenditures for individual types of projects within groups have evolved and do not prove any regularity. For example, the value of planned projects in group A was doubled although the amount of money spent for this purpose increased by only $60 \%$ During the following years, expenditure fell by $70 \%$ and rose again. In group B in 2012, expenses were very high and later were significantly reduced. The costs of group $\mathrm{C}$ reached 
a maximum in 2013 and the expenses of group D gradually declined starting in 2012. Expenses in group E were double than originally planned. Unfortunately, any regularities in costs incurred for each group could not be observed.

\section{Chart 1 | Total value of projects implemented by the chemical company within four years}

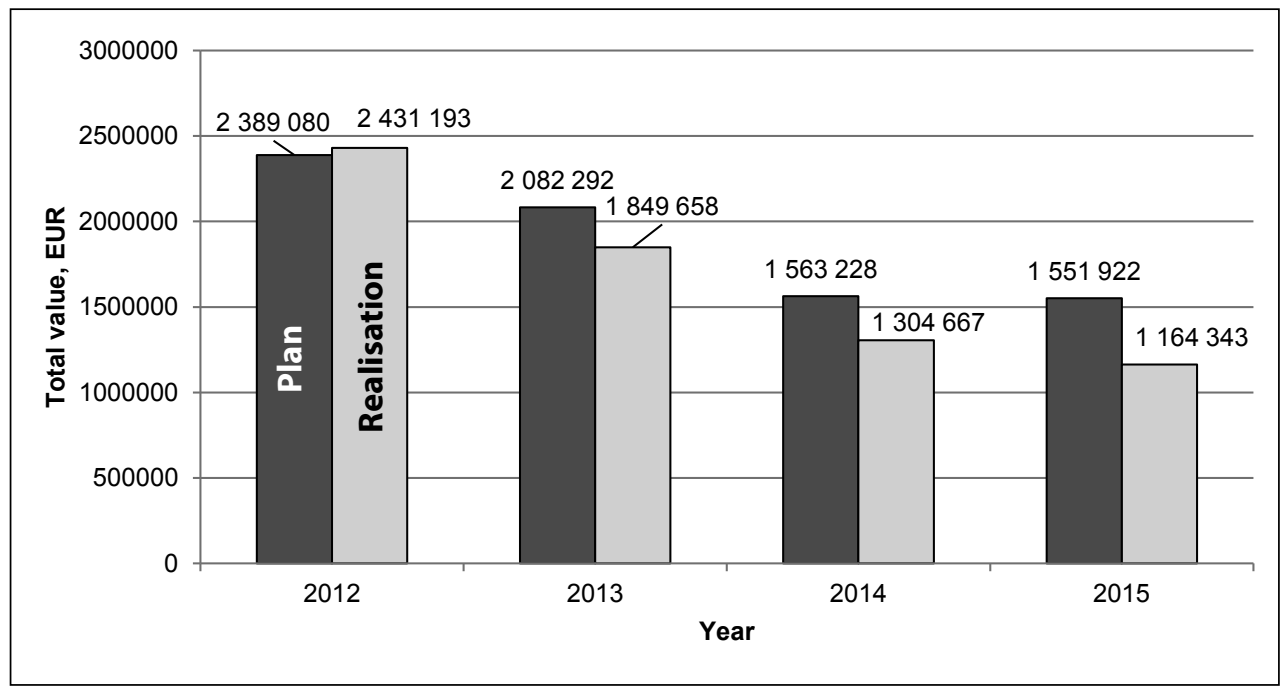

Source: authors' own calculation

Chart 2 | Average value of projects implemented by the chemical company within four years

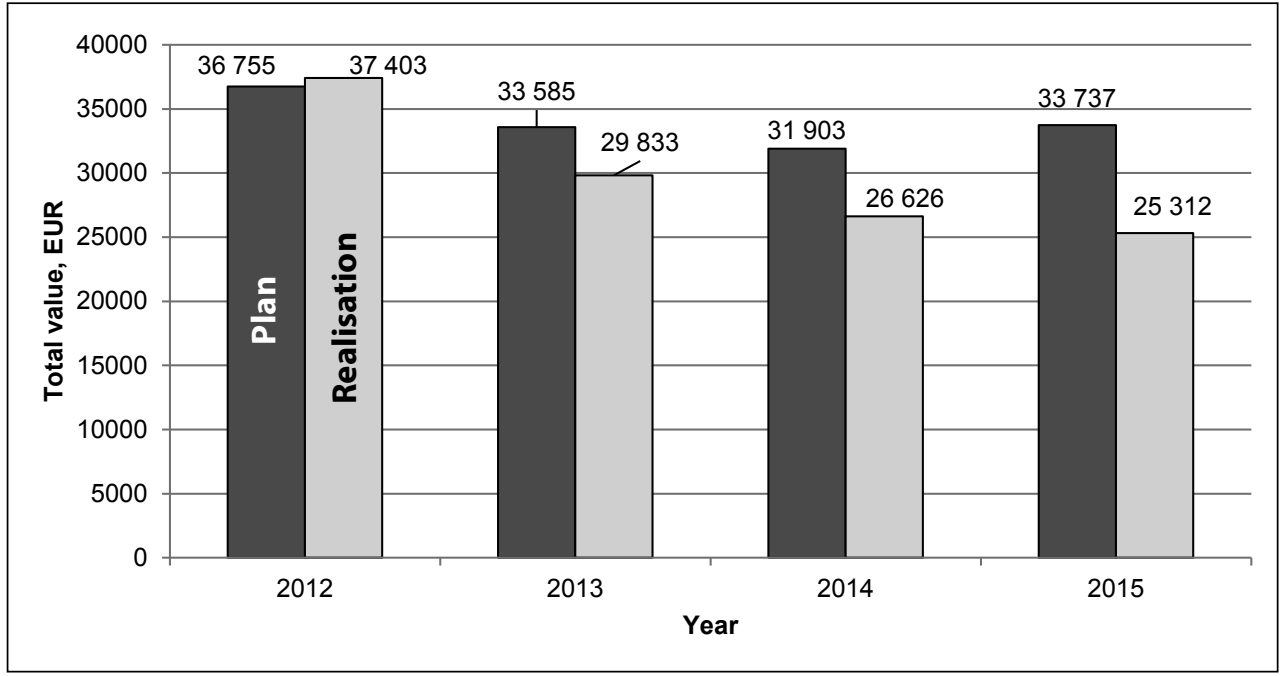

Source: authors' own calculation

An attempt was made to fit a theoretical probability distribution of relative cost overruns to data regarding the specific groups of projects implemented from 2012 to 2014 . However, this was impossible due to the limited number of projects assigned to particular groups. 
No valid fits were found for distributions. It was decided to prepare empirical distributions of cost overruns and take decisions on the basis of this. As an example, the distribution of cost overruns for group A is presented in Chart 3. Group A was selected because it was more uniform in terms of project types than other groups, so forecasting should be more accurate. On the basis of the presented distribution, the required increase in costs was prepared (Chart 4). Taking into account the $50 \%$ likelihood of overruns, the $10 \%$ uplift should be taken into account for group A in 2015. Indeed, the average cost overrun in 2015 was 9\%. The real data of project group A achieved in 2015 is presented in Table 1.

\section{Chart 3 | Empirical cost overruns distribution for group A based on 2012-2014 data}

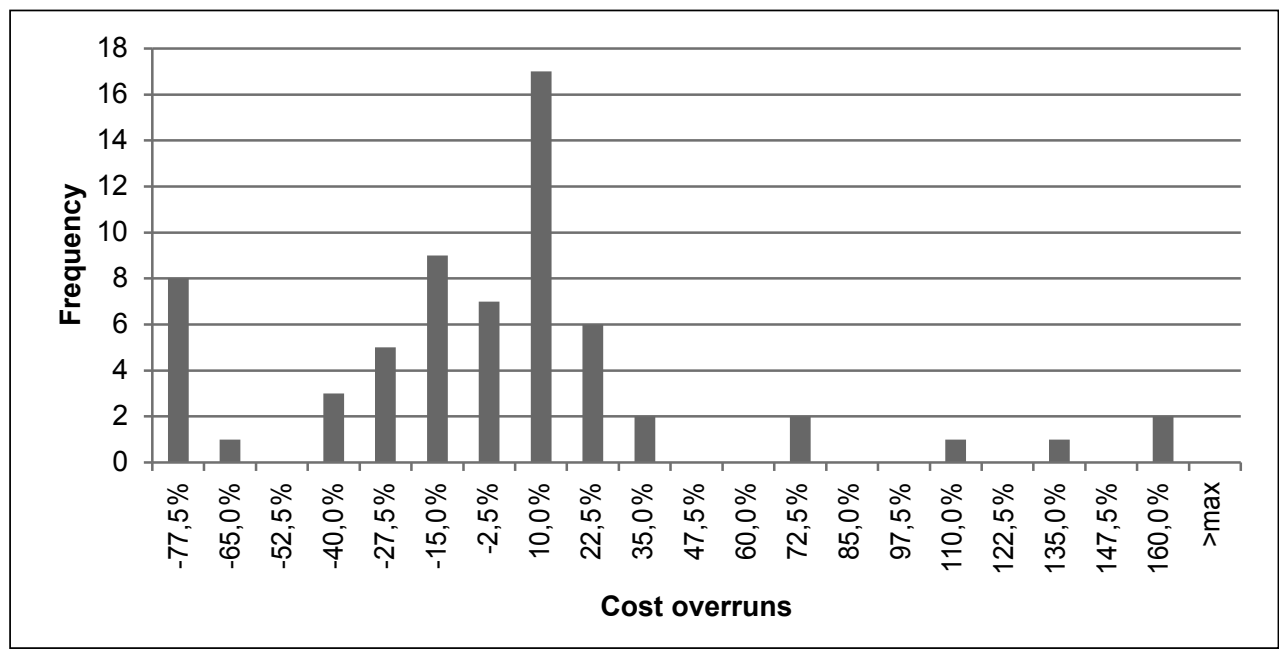

Source: authors' own calculation

\section{Chart 4 | Empirical cost overruns distribution for group A based on 2012-2014 data}

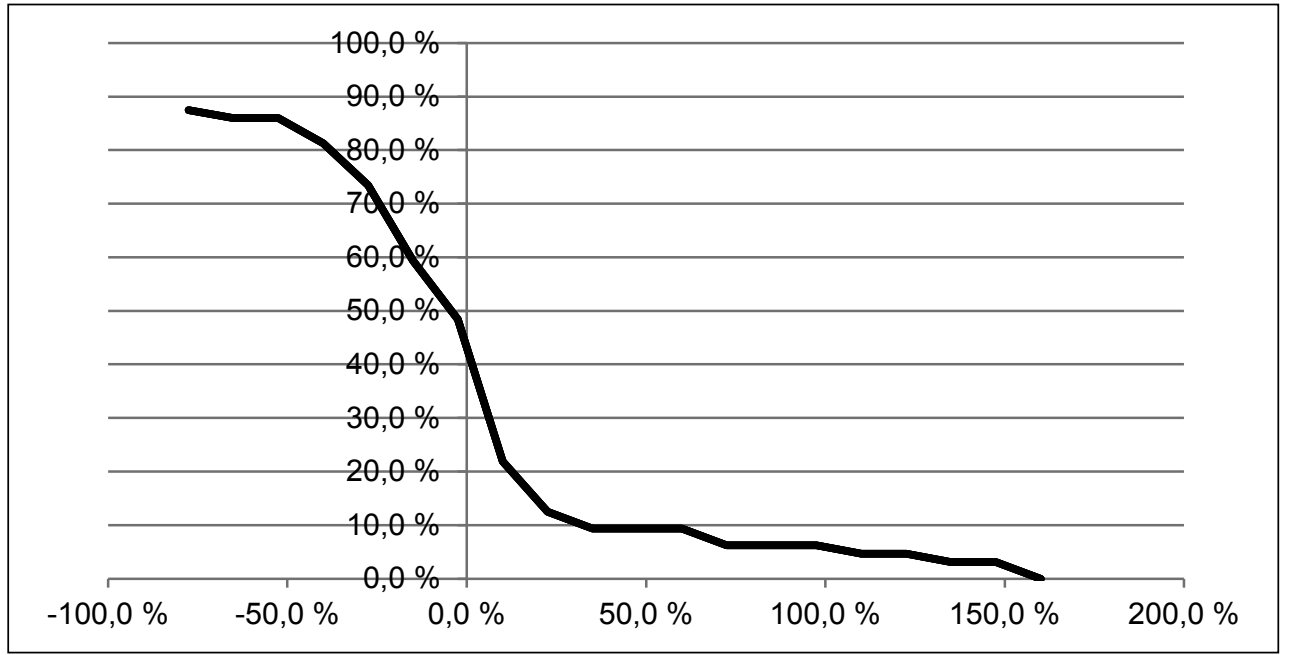

Source: authors' own calculation 
Table 1 | Costs and overruns of group A in 2015, in Euros

\begin{tabular}{|c|c|c|c|}
\hline Plan & Realisation & Cost increase & Relative overruns \\
\hline 3225 & 3189 & 36 & $-1 \%$ \\
\hline 9675 & 4580 & 5096 & $0 \%$ \\
\hline 7998 & 7985 & 13 & $-42 \%$ \\
\hline 18060 & 10417 & 7643 & $-9 \%$ \\
\hline 12900 & 11739 & 1161 & $-8 \%$ \\
\hline 23220 & 21337 & 1883 & $-27 \%$ \\
\hline 32250 & 23478 & 8772 & $0 \%$ \\
\hline 32250 & 32258 & -8 & $7 \%$ \\
\hline 32250 & 34404 & -2154 & $4 \%$ \\
\hline 37410 & 38744 & -1334 & $-20 \%$ \\
\hline 61920 & 49239 & 12681 & $-32 \%$ \\
\hline 193500 & 131584 & 61916 & $-12 \%$ \\
\hline
\end{tabular}

Source: authors' own calculation

\section{Conclusions}

The objective of this research was to use the method for small projects executed in the analysed chemical company. The value of the exercise comes from the fact that real data was investigated. However, the analysis of the exactness of cost plans versus the actual results did not lead to clear conclusions. In the presented case, it was impossible to compare statistical distributions of reference 2012-2014 data and costs incurred in 2015. The number of projects implemented by the company in each group was too small to make a correct inference. Large disparities especially arose in estimating the costs of long projects, which influenced the correlation. The Reference Class Forecasting Method matched the estimates very well for large homogeneous projects described in the literature when it was possible to separate uniform groups of projects. Using RCFM in a real business environment for a selected company implementing a limited number of various project types is impractical and does not provide reliable results. Despite the best endeavours to classify projects into groups to improve the homogeneity of the groups, the scope inside the groups proved to be too large. For such a company, we would instead recommend to predict future potential costs overruns on the basis of average data concerning previous years. We advise single companies to use historical data to improve the forecasting of overruns rather than employ RCFM. 


\section{References}

Abrams, J. B. (2010). Quantitative business valuation: A mathematical approach for today's professionals. 2nd ed. Hoboken, US: Wiley.

Dimov, I. T. and McKee, D. (2007). Monte Carlo methods for applied scientists. River Edge, NJ, USA: World Scientific.

Dinsmore, P. and Cabanis-Brewin, J. (2010). AMA handbook of project management. 3rd ed. Saranac Lake, NY, USA: AMACOM Books.

Flyvbjerg, B. (2003). Megaprojects and risk: An anatomy of ambition. Cambridge: Cambridge University Press.

Flyvbjerg, B. (2011). Over budget, over time, over and over again. In: P. W. Morris, J. K. Pinto and J. Söderlund, eds., The Oxford Handbook of Project Management, 1st ed. Oxford: Oxford University Press, pp. 321-344.

Flyvbjerg, B., Skamris Holm, M. and Buhl, S. (2002). Underestimating Costs in Public Works Projects: Error or Lie? Journal of the American Planning Association, 68(3), pp. 279-295, https://doi.org/10.1080/01944360208976273

Flyvbjerg, B., Skamris Holm, M. and Buhl, S. (2004). What Causes Cost Overrun in Transport Infrastructure Projects? Transport Reviews, 24(1), pp. 3-18, https://doi.org/10.1080/0144164032000080494a

Flyvbjerg, B., Skamris Holm, M. and Buhl, S. (2005). How (In)accurate Are Demand Forecasts in Public Works Projects? Journal of the American Planning Association, 71(2), pp. 131-146, https://doi.org/10.1080/01944360508976688

Fridgeirsson, T. V. (2009). The Use of Reference Classes to Forecast Risk and Uncertainty in Icelandic Projects. In: Proceedings of the 5th Nordic Conference on Construction Economics and Organisation. [online] Reykjavík: Reykjavík University, pp. 117-124. Available at: http://www.ru.is/media/publications/SoSE/5NC-2009-VOL-2.pdf\#page=118 [Accessed 4 Feb. 2017].

Goldratt, E. M. (1997). Critical chain. Great Barrington, MA: North River Press.

Hastie, S. and Wojewoda, S. (2015). Standish Group 2015 Chaos Report, [online]. Available at: https://www.infoq.com/articles/standish-chaos-2015 [Accessed 4 Feb. 2017].

Hinde, D. (2012). PRINCE2 study guide. Hoboken: Sybex.

Kahneman, D. (2011). Thinking, fast and slow. Kindle edition. New York: Farrar, Straus and Giroux.

Kahneman, D. and Tversky, A. (2000). Choices, values and frames. New York: Cambridge University Press.

Leach, L. P. (2014). Critical chain project management. 3rd ed. Norwood, MA, USA: Artech House.

Office of Government Commerce (OGC), (2009). Managing successful projects with PRINCE2. London: Stationery Office Books.

PMBOK, (2008). A guide to project management. Body of knowledge. Upper Derby: Project Management Institute Standard Committee.

Stackpole, C. S. (2013). PMP certification all-in-one for dummies. Somerset, US: Wiley. 